\title{
Uma reflexão sobre a formação do professor da escola básica*
}

José Mário Pires Azanha

\section{A questão dos fundamentos da formação docente}

Há décadas discute-se em congressos, seminários, cursos e outros eventos semelhantes, qual a formação ideal ou necessária do professor do ensino básico (fundamental e médio), numa demonstração ostensiva de insatisfação generalizada com relação aos modelos formativos vigentes, principalmente nos cursos de licenciatura.

No entanto, dessa ampla e continuada discussão, não têm emergido propostas que ultrapassem o nível de recomendações abstratas sobre a necessidade de "sólida formação dos educadores", da "integração de teoria e prática”, da "interdisciplinaridade" etc. É claro que sugestões dessa natureza são capazes de entreter colóquios e debates, mas a sua utilidade não vai além desses efeitos retóricos.

Nessas discussões, quase sempre se parte de uma noção vaga e impressionista de "escola brasileira”, caminha-se para a afirmação da necessidade de uma "política nacional de formação de professores" e, em seguida, desenha-se o "perfil profissional" desses professores por meio de um arrolamento de competências cognitivas e docentes que deveriam ser desenvolvidas pelos cursos formadores. Embora esse traçado das discussões seja um pouco simplificado, ele capta duas tendências sempre presentes no encaminhamento do tema da formação de professores: o vezo centralizador das normas gerais e a fixação na figura individual do professor.

Com relação à primeira tendência, talvez seja sensato convir que, num país com tão grandes diferenças econômicas, sociais e culturais, a única política nacional de formação de professores deva ser uma simples indicação de rumos, tal como a própria LDB já fez. Ultrapas- sar esse limite e tentar estabelecer normas gerais pode acabar conduzindo à formulação de um modelo abstrato inviável na ampla variedade da situação nacional.

Quanto à segunda tendência, o problema é ainda mais grave porque as discussões e propostas que surgem em congressos, seminários e outros eventos têm se detido na caracterização da figura abstrata de um profissional dotado de determinadas qualidades como sendo um ideal de formação.

Nessa linha, as preocupações sobre a formação docente aproximam-se da concepção de Comênio (Didática Magna, 1657), segundo a qual o "bom professor" seria aquele capaz de dominar a "arte de ensinar tudo a todos". Comênio, como um baconista convicto, tinha uma profunda confiança no poder do método, achava possivel que a arte de ensinar fosse codificável num conjunto de prescrições cuja observância estrita faria de uma pessoa interessada um professor competente, ele queria implantar no campo da educação a reforma pretendida por Bacon no domínio das ciências. Como para Bacon fazer ciência era aplicar um método, Comênio imaginou que ensinar era também a aplicação de um método.

Contudo, quando Comênio falava em método de ensino era no sentido claro e forte de uma transposição para a educação da concepção baconiana de método científico. Essa idéia, embora equivocada, pois respaldava-se numa discutível analogia entre o desenvolvimento do conhecimento individual e o desenvolvimento social da ciência, sobreviveu pelo menos até os trabalhos de John Dewey, neste século. Mas, nos

\footnotetext{
* Este texto foi apresentado como uma indicação (n. 07/2000) ao Conselho Estadual de Educação do Estado de São Paulo em 21/06/2000 e serviu de fundamento para a elaboração da deliberação CEE 08/2000.
} 
últimos tempos, essa vinculação direta entre método de conhecimento e método de ensino teve o seu significado original substituído por uma pletora de metáforas sobre conhecimento das quais se fazem enigmáticas ilações sobre ensino.

No que diz respeito às propostas de formação docente, o estado de coisas está tão desarranjado que, quando se fala em metodologias e estratégias de ensino, não se consegue discernir entre possíveis relações conceituais entre conhecimento, ensino e valores e hipotéticas relações entre capacidade de aprender e supostas fases de desenvolvimento psicológico. Enfim, nem sempre se procura e se consegue distinguir entre o que são exercícios de um jargão na moda daquilo que tem respaldo em investigações teóricas e empíricas.

A idéia de que ensino eficaz é basicamente a aplicação competente de um saber metodológico, epistemologicamente fundamentado em outros saberes, principalmente de natureza psicológica, é altamente discutível.

Teorias da aprendizagem, da inteligência e do desenvolvimento cognitivo e emocional da criança e do adolescente aparecem, entram em moda e saem de moda. Pouco há de seguro, nessas áreas do conhecimento, que permita fundamentar a formação do professor. Além disso, é preciso ainda chamar a atenção para o fato de que tentativas de derivar regras práticas de teorias científicas são, na maior parte das vezes, exercícios claudicantes do ponto de vista lógico, por desconsideração das complexas questões implicadas no trânsito entre o conhecimento de fatos e possíveis regras que consistiriam numa aplicação desse conhecimento.

Essas duas dificuldades - a insuficiente comprovação empírica de teorias disponíveis sobre as várias dimensões do fenômeno educativo e o embaraço lógico de derivar dessas teorias recomendações metodológicas inequívocas sugerem que talvez não convenha alicerçar a formação de docentes sobre terreno tão movediço. Mas, além dessas questões científicas e lógicas, é preciso levar em conta que, mesmo naqueles casos em que reiteradas comprovações empíricas parecem dar sustentação e credibilidade a algumas teorias ou hipóteses científicas, permanece a questão propriamente educacional de saber se uma determinada atuação pedagógica deve ser posta em prática apenas porque teria algum respaldo científico. 0 valor de programas educacionais exige uma avaliação mais abrangente. Enfim, a validade científica de uma teoria não constitui base suficiente para formulação de diretrizes educativas que sempre exigem opções entre valores. Pense-se, por exemplo, na educação sexual, que jamais poderá ser conduzida a partir apenas de informações sobre desenvolvimento e fisiologia do sexo.

Esse é o ponto que realmente importa. A adequada formação do professor não pode ser imaginada como a simples e direta aplicação à situação de ensino de um saber teórico. Não se trata de substituir uma orientação psicológica por outra nem de ampliar os estudos de ciências sociais como a Sociologia, a Antropologia e outras.

0 ponto de vista pedagógico não é uma soma de parcelas de saberes teóricos que, embora necessários, nunca serão suficientes para alicerçar a compreensão da situação escolar e a formação do discernimento do educador. Nesses termos, é claro que não há fórmulas prontas para orientar essa formação, mas o próprio conceito de vida escolar é básico para que se alcance esse discernimento.

Aliás, Scheffler, no livro A linguagem da educação (Saraiva/EDUSP, 1974, p. 45), após examinar os enganos lógicos das tentativas de derivar diretrizes educacionais de concepções filosóficas de homem, mostra que

Uma observação análoga vale para a transferência de definições da ciência para a educação, transferência essa cujos perigos já notificamos. Observamos que as definições científicas estão em continuidade com as teorias e com as evidências próprias aos seus domínios respectivos, e que o melhor, portanto, é que sejam tratadas à parte. (...) Elas devem ser julgadas, grosso 
modo, pela contribuição que fazem à adequação das suas respectivas redes científicas com relação à explicação dos fatos. Segue-se daí que adotar uma definição científica para uso programático não significa evitar a necessidade de uma avaliação do programa que esse uso veicula. A adequação científica de uma definição não é um signo do valor prático de tal programa (...).

Além das considerações anteriores, uma outra crítica muito grave que se pode fazer às diferentes propostas de bases teóricas da formação docente está na unanimidade que apresentam ao focalizar a figura individual do professor. Traçar o perfil profissional do professor, detentor de determinadas competências cognitivas e docentes, é um exercício pedagógico para esboçar um "retrato imaginado" do que seria o professor universal. Esse exercício seria tão útil para a educação quanto a descrição do "espírito científico" para a ciência.

\section{A “natureza” da relação pedagógica}

A maciça expansão das matrículas no ensino fundamental desde há trinta anos, e no ensino médio mais recentemente, inviabilizaram uma concepção da atividade de ensino fundada na relação professor-aluno, na qual a imagem do "bom professor" era basicamente a daquele profissional que dominava um saber disciplinar que seria transmitido a um discípulo. 0 êxito desse ensino dependia - pensava-se - de uma combinação de conhecimento disciplinar e de preparo didático do professor. No quadro dessa concepção, nasceram e permaneceram durante muitos anos os cursos de licenciatura no ensino superior brasileiro e em outros países. No Brasil, a explosiva expansão do ensino de $1^{\circ} \mathrm{grau}$, desde 1971, exigiu também a expansão acelerada dos cursos de licenciatura que simplesmente disseminaram o modelo associado a essa concepção.

Refletindo em grande parte as aflições norte-americanas com a corrida espacial no final da década de 50, houve uma forte preocupação com a qualidade do ensino de ciências, de matemática e, por contaminação, com a das demais disciplinas no ensino fundamental e médio. Por razões que ainda não estão suficientemente estudadas, essa pretendida qualidade foi interpretada como uma questão a ser resolvida metodologicamente, por meio de procedimentos de ensino supostamente mais eficazes porque seriam apoiados em teorias psicológicas do desenvolvimento e da aprendizagem. 0 impacto dessas idéias influiu fortemente nos cursos de licenciatura, ampliando substantivamente o espaço curricular de disciplinas vinculadas às temáticas específicas de feição metodológica e psicológica. Obviamente, tudo isso reforçou uma concepção de ensino preceptorial fundada numa relação pessoal entre professor e aluno.

0 fulcro do problema, que ainda permanece, está no caráter abstrato da concepção da relação pedagógica como se ela fosse uma relação entre dois - aquele que ensina e aquele que aprende -, abstraída do contexto institucional. Ao considerar que a relação pedagógica pode ser orientada a partir de teorias que pretendem descrever e explicar a natureza do conhecimento, que o professor ensina, e a natureza da aprendizagem, que o aluno desenvolve, essa idéia ganha a fisionomia de um jogo abstrato entre parceiros abstratos: o preceptor e o discípulo. Na escola contemporânea, seja ela pública ou privada, o professor individual que ensina e o aluno individual que aprende são ficções; seres tão imaginários quanto aqueles a que se referem expressões como "homo oeconomicus", "aluno médio", "sujeito epistêmico" e outras semelhantes. Não se trata de discutir a necessidade teórica ou prática de conceitos gerais abstratos, mas a utilidade que eles possam ter para fundamentar e orientar práticas docentes que devem ocorrer em situações escolares concretas muito diferentes entre si. No atual quadro histórico - de ascensão das massas a uma educação cada vez mais ampliada - não há lugar para essa visão elitista e petrificada da relação pedagógica. 
Aliás, desde sua origem, a relação pedagógica preceptorial foi uma condição distintiva das elites, embora, ao longo dos séculos, tanto o preceptor como o seu discípulo tenham sido figuras sociais diferentes; num momento, eram o monge e o noviço, num outro, o cavaleiro e o pajem, num outro ainda, o homem de letras e o príncipe da casa real ou o filho do nobre etc.

A relação pedagógica preceptorial nunca foi, na verdade, uma relação escolar, isto é, o seu contorno social natural não era a escola, mas a casa, o convento, o castelo etc. Há algumas décadas, no Brasil principalmente, para a nascente e escassa escola pública pretendeu-se - e se conseguiu, em parte - transplantar um estilo de relacionamento pedagógico que era, no seu aspecto geral, uma espécie de "preceptorado coletivo". Hoje, porém, a grande expansão do ensino fundamental deu origem a um tipo de escola que é uma novidade institucional, na qual as relações pedagógicas possíveis não podem ser modeladas a partir apenas de métodos e procedimentos de alguém que ensina e de habilidades, competências e qualidades psicológicas de alguém que aprende.

A própria relação preceptorial desapareceu como instituição educativa, mas não sem deixar vestígios numa concepção idealizada da relação pedagógica. No entanto, essa contraposição entre a figura do preceptor e a do professor não pode ter uma interpretação simplificada, que consistiria na idéia de que aquele estaria apenas empenhado numa relação de ensino individual, enquanto este, numa relação de ensino coletivo. Essa passagem do ensino de feição preceptorial para o ensino escolar é muito complexa e não se reduz à questão didática de um ensino individualizado versus um ensino coletivizado. Essa redução seria fruto de uma confusão entre individual e privado e entre coletivo e público, obscurecendo o fato essencial de que o preceptor era um agente da família e a escola é um agente social.

Como disse Hannah Arendt (Entre o passado e o futuro, Perspectiva, 1972, p. 238-9), a escola é a instituição que interpomos entre o domínio privado do lar e o mundo com o fito de fazer que seja possível a transição, de alguma forma, da família para o mundo. Aqui, o comparecimento não é exigido pela família, e sim pelo Estado, isto é, o mundo público, e assim, em relação à criança, a escola representa em certo sentido o mundo (...).

0 preceptor atuava em nome da família, o professor atua na escola (estatal ou particular) em nome de um mundo público. Por isso, não é suficiente contrapor o caráter individual do ensino preceptorial ao caráter coletivo do ensino escolar.

A escola contemporânea é, pois, uma novidade social e cultural. Nesse novo espaço institucional, o desempenho do professor não mais pode ser pensado como uma simples questão de formação teórica de alguém que ensina, como também o desempenho do aluno não mais pode ser considerado como uma simples questão de motivação e de esforços individuais. A escola de hoje é uma ruptura com a escola do passado, sempre inspirada numa visão preceptorial da relação pedagógica. Analogamente, a família contemporânea é uma novidade social e cultural em comparação com a família de algumas décadas atrás. As relações entre pais e filhos, nessa nova situação, não podem tomar como modelo aquelas vigentes no passado.

Tanto no que diz respeito à escola como no que se relaciona com a família houve mudanças e rupturas institucionais. Descrever esse quadro como sendo de crise é uma apreciação valorativa que pode ser um descaminho teórico de análise e de investigações empíricas e, por isso mesmo, conducente a sérios equívocos na fixação de diretrizes de atuação na esfera pública ou privada.

A emergência de novidades não é necessariamente uma indicação de crises institucionais, mas talvez apenas de mudanças sociais inerentes aos quadros da sociedade contemporânea. No caso da escola, haveria crise se o mundo escolar, que tem uma subcultura própria, permanecesse 
imobilizado num momento que é caracterizado por fortes mudanças sociais e culturais.

A escola básica de hoje não é pois um retrocesso com relação à escola de ontem. É uma outra escola, principalmente por ser altamente expandida, e suas alegadas deficiências precisam ser enfrentadas por um esforço permanente de investigação e busca.

Nesse quadro, a questão da formação docente não será convenientemente encaminhada se insistirmos na busca alquímica de panacéias pedagógicas. Não há dúvida de que o professor deve ser um profissional competente, mas não há uma "estrada real" para conseguir esse desiderato. "Escola brasileira” é uma expressão excessivamente abstrata para ter poder descritivo; consequentemente, uma política nacional de formação docente poderá ser um malogro se ignorar a imensa variedade da situação escolar brasileira.

As instituições formadoras de docentes têm de ver nessa variedade o ponto de partida para formular suas propostas. Diferentemente de outras situações profissionais, o exercício da profissão de ensinar só é possível no quadro institucional da escola, que deve ser o centro das preocupações teóricas e das atividades práticas em cursos de formação de professores. 0 professor precisa ser formado para enfrentar os desafios da novidade escolar contemporânea.

Nessas condições, qualquer proposta de formação docente deve ter um sentido de investigação e de busca de novos caminhos. A premência do problema educacional não justifica o apressamento de soluções, que devem ter sempre o caráter de tentativas. Nos casos dos cursos de licenciatura, em face dos desafios desse novo quadro institucional, não há respostas teóricas ou modelos práticos que possam orientar com segurança qualquer esforço de renovação de currículos, programas e métodos. A única certeza é que não há certezas.

Novas propostas de formação docente devem partir do próprio conceito de escola, não apenas como é formulado pela eventual contribuição de teorias da Sociologia, da Antro- pologia, da Administração e de outras áreas do conhecimento que se propõem descrever e explicar os "fatos" da vida escolar, mas também pelo desenvolvimento de um ponto de vista pedagógico que leve em conta esses fatos na ordenação desejável das atividades escolares.

Comunidades sociais como igrejas, partidos políticos, Forças Armadas, associações culturais ou recreativas e outras têm semelhanças com a escola básica porque, como esta, são instituições empenhadas, de alguma forma, num esforço de ensino e de transmissão cultural. Mas a escola tem um traço que a singulariza: a escolarização básica, que alcança a todos numa sociedade democrática, deve deixarse impregnar extensivamente pela herança cultural e não pela parcialidade de propósitos doutrinários, ideológicos ou de cultivo e de preparação para atividades específicas.

Outro traço distintivo da escola é que ela sempre tem endereço e vizinhança, o que afeta profundamente a sua convivência social interna, muito além do que é possível ou desejável em outras instituições. Cada escola, mesmo quando integra um sistema, desenvolve uma comunhão espiritual a partir do seu enraizamento numa situação local. Como disse M. Oakeshott,

a idéia de 'escola' é a de uma comunidade histórica de professores e alunos, nem muito grande nem muito pequena, com tradições próprias que dão origem a lealdades, obrigações e sentimentos dedicados a iniciar sucessivas gerações de recémchegados à condição humana (Education: The engagement and its frustration. In: Education and the development of reason, Dearden, R.S. (org), Routledge e Kegan Paul, Londres, 1972, p. 26).

0 ponto de vista pedagógico não deve, pois, ser uma tentativa de aplicação de conhecimentos auferidos em possíveis descrições e explicações de "fatos" escolares, mas um esforço de compreensão da escola como um projeto institucional para transformar uma comunidade de professores e alunos onde ocorrem encontros 
de gerações numa comunidade espiritual fundada numa visão ética cujos efeitos educativos se prolongam além dos anos de escolaridade.

\section{O novo quadro legal da formação docente}

1. Quando a primeira Lei de Diretrizes e Bases da educação nacional (Lei n. 4.024/61) foi finalmente sancionada, Anísio Teixeira publicou um breve artigo no Diário de Pernambuco (reproduzido na RBEP, vol. XXXV11, n. 86), cujo título é "Meia vitória, mas vitória". Nele o grande educador saudava a nova lei que, embora não “à altura das circunstâncias”, era "resultado de uma luta em que as pequenas mudanças registradas constituem vitórias e não dádivas ou modificações arbitrárias do legislador".

Trinta e cinco anos depois foi finalmente sancionada uma nova lei (n. 9.394), que revogou não apenas a Lei n. 4.024, mas também algumas outras que versavam sobre a temática das diretrizes e bases da educação nacional. Não se pretende aqui um estudo comparativo entre a nova lei e as anteriores, mas apenas assinalar que pelo menos em alguns pontos o que se conseguiu não foi uma "meia vitória", porém um grande avanço.

Pela primeira vez na legislação brasileira focalizaram-se as questões da autonomia da escola e de sua proposta pedagógica. 0 Art. 12, inciso 1, estabelece como incumbência principal da escola a elaboração e a execução de sua proposta pedagógica e o Art. 13, inciso 1, e o Art. 14, incisos 1 e 11, estabelecem que essa proposta é uma tarefa coletiva da qual devem participar professores, outros profissionais da educação e as comunidades escolar e local.

A relevância dessa abertura legal é maior para a escola pública que, a não ser em raríssimas exceções, integra uma rede cuja administração centralizada tem uma vocação intervencionista que, continuamente, trata como homogêneas situações escolares substantiva- mente heterogêneas e pretende eliminar diferenças por ordenações regulamentadoras burocráticas que, arrogantemente, confundem poder administrativo com discernimento pedagógico. Tendo em vista quadro semelhante, Anísio Teixeira, já em 1962, alertava:

"É por isto mesmo que tais pequenas vitórias precisam ser consolidadas na sua execução. Não se julgue que isto seja automático. Se não houver visão e vigilância no cumprimento da lei, a máquina administrativa poderá vir a burlá-la completamente."

A necessidade da advertência torna-se maior quando já não se trata de "pequenas vitórias”, mas da grande mudança que a nova lei introduziu ao preconizar que cada escola tenha autonomia para elaboração de sua própria proposta pedagógica. Se não houver "visão e vigilância”, a inovação ensejada pela lei poderá ter como resultado apenas mais uma imposição de papelada. Haja vista a escassa conseqüência que teve a introdução na rede pública paulista, no início de 1970, da idéia de planejamento das atividades escolares como preliminar ao ano letivo (Decreto de 29/ 01/70 - Dispõe sobre planejamento de atividades escolares no ensino primário e médio). Aliás, na escola pública brasileira sempre houve pouca compreensão do caráter coletivo do trabalho escolar, provavelmente como reflexo da concepção que focaliza esse trabalho como se fosse principalmente uma relação entre professor e aluno. A idéia de que uma boa escola é mais do que a simples reunião de bons professores tem sido de difícil penetração nas práticas escolares. Na verdade, tal como sempre ocorreu nos cursos normal e de licenciatura, nem se suspeita que essas práticas possam ser algo mais do que ensino do aluno. 0 próprio período de planejamento escolar cuja introdução pioneira no ensino público paulista tinha por motivação a criação de uma oportunidade de trabalho conjunto da escola - na sua implantação transformou-se numa rotina burocratizada que, nos casos de execução com seriedade e êxito, não passou de for- 
mulação e apresentação de planos individuais de professores empenhados numa renovação metodológica de suas próprias disciplinas. Esse tipo de resultado, não obstante o seu próprio mérito, não contempla e não aproveita as possibilidades que a nova LDB delineou na atribuição, como tarefa principal da escola, da elaboração e execução da sua proposta pedagógica. Essa tarefa consiste principalmente na definição dos problemas prioritários da escola. É neste momento que é indispensável o que Anísio Teixeira chamou de "visão e vigilância” para resistir às arremetidas burocratizantes e, também, aos pruridos cienticistas dos "diagnósticos" e "levantamentos" intermináveis e inconclusivos. Os problemas da escola são simplesmente aqueles que assim são percebidos pelas comunidades escolar e local. Haverá, nessa percepção, enganos, distorções, exageros etc. Mas é aí que se instala a grande oportunidade para início da função educativa de cada escola para construir a sua identidade institucional, identificando e tentando resolver os seus problemas. Como dizia Mestre Anísio: "afinal, é na escola que se trava a última batalha contra as resistências de um país à mudança”.

Para se opor às resistências à mudança, o professor deve ser formado não como um portador de verdades a serem aplicadas a uma situação escolar abstrata, mas incentivado a procurá-las na variedade social e cultural de escolas concretas.

2. Atualmente, entretanto, há um outro perigo inexistente naqueles tempos. Hoje, há um fervor mudancista que pode acabar atropelando as reais oportunidades de mudança criadas pela Lei n. 9.394/96. Essas oportunidades podem ser agrupadas, de um modo sumário, em dois grandes blocos: o primeiro contém modificações que tornaram mais flexíveis regulamentações anteriores muito rígidas e minuciosas, que ignoravam a imensa variedade de situações educacionais no país; o segundo bloco abrange dispositivos cuja novidade reside no delineamento de possibilidades institucionais que, se bem aproveitadas, poderão trazer algumas mudanças radicais na educação brasileira. Dentre essas possibilidades, uma, como já vimos, é a atribuição à própria escola da competência de elaboração de sua proposta pedagógica; outras vinculam-se à criação de novos cursos e instituições escolares.

Com relação a estas últimas, os órgãos administrativos e normativos de níveis federal e estaduais deveriam atuar com muita cautela e discernimento para não baralhar casos de adequação de normas, conforme prazos estabelecidos no Art. 88 e parágrafos, e aqueles outros referentes ao aproveitamento de novas possibilidades criadas pela LDB.

Sem criteriosa distinção entre esses casos, corre-se o risco de edição açodada de regulamentações frustradoras de iniciativas interessantes dos próprios sistemas escolares. Esse risco não é imaginário e infelizmente em ocasiões anteriores revelou-se muito concreto. Seria de toda conveniência que antes de qualquer regulamentação de uma simples possibilidade legal, houvesse um exame abrangente do quadro institucional atual que indicasse suas realizações e suas lacunas. Na verdade, já existem muitos estudos que podem permitir um criterioso ajuizamento das deficiências e possibilidades de melhoria das instituições existentes. Não convém modificar o quadro atual sem uma visão clara do que se quer e de por que se quer. Ainda está na memória de todos o estrago institucional feito a partir da Lei n. 5.692/71, quando o antigo e respeitável curso normal foi substituído por uma mal concebida e confusa "habilitação para o magistério" no ensino de $2^{\circ}$ grau.

Em face dessas breves e preocupadas considerações, o Conselho Estadual de Educação de São Paulo (CEE) propõe, nesta indicação, apenas delinear um quadro conceitual básico para que a questão da possibilidade legal de uma nova instituição formadora de professores, como é o caso dos institutos superiores de 
educação, possa ser encaminhada de maneira interessante, sem nenhum atropelo das instituições existentes. Ao contrário, o que se quer é que as experiências já acumuladas possam de forma crítica convergir para uma efetiva busca de renovação institucional. 0 CEE está convencido de que essa renovação somente deverá ser induzida e não imposta, para que haja a mobilização de adesões críticas e não a de resistências legítimas da parte do magistério.

0 Art. 62 da LDB é muito claro a respeito das instituições formadoras de docentes, em nível superior, para atuar na educação básica. Somente haverá dois caminhos para essa formação: a) aquela oferecida pelas universidades e b) aquela a ser ministrada em institutos superiores de educação. Dentro de um certo prazo - que a lei não estabelece qual seja haverá apenas esses dois caminhos. Não convém, porém, que esse prazo seja muito curto, pois dentro dele devem ocorrer duas modificações muito importantes no quadro institucional de formação de docentes: a implantação de institutos superiores de educação e o conseqüente desaparecimento de cursos de licenciatura não universitários, isto é, ministrados em unidades de ensino superior não integrados numa universidade.

Essas modificações deverão ocorrer de forma seqüencial e gradativa para que a implantação da nova instituição de formação não seja uma operação cosmética de simples mudança de nomes de cursos isolados existentes. A implantação da nova instituição emergente não pode ser feita tumultuadamente absorvendo os defeitos de grande parte dos atuais cursos de licenciatura. Como ilustração desse risco, tome-se, por exemplo, o problema da integração de teoria e prática que seguramente não ocorrerá pelo simples aumento exor-bitante do número de horas da parte prática dos cursos. Sem uma revisão conceitual do que se entende por "prática", o aumento do número de horas poderá provocar apenas um raleamento da formação teórica sem nenhum ganho assegurado. Aliás, essa revisão conceitual deve ser abran- gente e incluir obrigatoriamente o próprio conceito de relação pedagógica.

3. 0 que se depreende da leitura do Art. 62 da LDB é que o legislador distinguiu claramente entre a formação docente que se dá no âmbito das universidades daquela que ocorrerá numa nova instituição, o instituto superior de educação. Com essa distinção prevaleceu a sensatez de permitir que o ensaio de criação de nova instituição possa ser feito sem eventuais e desnecessários conflitos com as instituições universitárias, detentoras de uma experiência acumulada na formação de docentes do ensino básico, em nível superior. Os institutos isolados de ensino superior, sem carreiras de pessoal docente e sem nenhuma preocupação sistemática de titulação de seus professores em nível de mestrado e doutorado, não chegaram a acumular num sentido positivo experiências de formação de docentes para o ensino básico, embora sejam os grandes provedores desses quadros e, em alguns casos, há muito tempo. É, pois, nesse ponto nevrálgico dos sistemas brasileiros de formação de professores que se localiza a oportunidade histórica de uma mudança substantiva no quadro institucional dessa formação.

As escolas isoladas de ensino superior, particulares e municipais, - inclusive aquelas mais antigas - nunca tiveram autênticos projetos de formação de professores nem se preocuparam em reunir condições materiais e humanas que favorecessem um ensino atualizado e de boa qualidade. Essas escolas nunca tiveram boas bibliotecas e o corpo docente sempre foi improvisado, a partir de circunstâncias locais, mal remunerado e sem nenhuma perspectiva de carreira. Essa descrição sumária poderá até ser injusta para algumas escolas, mas não é para a grande maioria delas.

Esse quadro sedimentado de improvisações, erros e descaso com as questões básicas da formação de docentes nos cursos não universitários de licenciatura reclama hoje uma tentativa radical de mudança institucional, possibilitada agora pelo 
Art. 62 ao distinguir entre a universidade que, na sua autonomia, buscará seus próprios caminhos de reorganização da formação de professores, e os institutos superiores de educação que, fora do âmbito e do peso das estruturas universitárias, representarão a alternativa histórica de um ensaio institucional inteiramente aberto a novas idéias sobre a formação docente.

Embora as universidades públicas paulistas não possam contrapor à indigência pedagógica dos cursos isolados de licenciatura a excelência dos seus próprios cursos, é inegável, por outro lado, que essas universidades consolidaram, ao longo dos anos, boas condições materiais e humanas de ensino e de pesquisa e instituíram carreiras vinculadas a concursos, a programas de titulação acadêmica e de intercâmbio nacional e internacional. Como conseqüência da reunião dessas condições, esse pequeno grupo de universidades públicas mais outro pequeno grupo de universidades privadas têm mantido viva a preocupação com a questão da formação de docentes para a rede de escolas básicas, credenciando-se assim a um papel de liderança na busca e no encaminhamento de soluções para esse problema, por meio da criação de institutos superiores de educação.

Com base nessas considerações, o Conselho Estadual de Educação entende que essa ten- tativa radical de uma mudança institucional deverá ser feita a partir de um projeto institucional que congregue, esforços de três instâncias:

- entidades mantenedoras de escolas municipais de ensino superior ou de escolas estaduais isoladas de ensino superior;

- órgãos centrais da administração pública da educação, estadual ou municipal; e/ou

- universidades públicas.

É preciso não confundir a idéia desse projeto institucional com a singeleza de uma proposta pedagógica que cada escola básica deve elaborar para enfrentamento de seus próprios problemas. Cada projeto institucional será resultado de uma complexa negociação entre as entidades participantes com vistas a esboçar a fisionomia de uma nova instituição formadora a partir de uma clara concepção do professor do ensino básico.

Haverá tantos projetos institucionais quantos institutos superiores de educação forem previstos numa primeira fase. Cada um desses projetos disciplinará a implantação autônoma de uma nova instituição formadora, o que permitirá que, no fundo, haja diferentes experiências institucionais que apenas serão uniformes quanto às recomendações básicas do CEE, a serem fixadas por uma deliberação que disporá, em termos amplos e flexiveis, sobre os componentes indispensáveis desses projetos.

\section{DELIBERAÇÃo CEE No 08/2000}

Dispõe sobre credenciamento de Institutos Superiores de Educação no sistema de ensino do Estado de São Paulo.

Art $^{0} 1^{\circ}$ - A formação de professor para o ensino básico far-se-á em licenciaturas plenas em universidades, centros universitários e institutos superiores de educação.

Parágrafo único - Para a educação infantil e para as séries de primeira à quarta do ensino fundamental essa formação far-se-á também em curso normal de nível médio.

Art $^{\circ} 2^{\circ}$ - Os institutos superiores de educação manterão:

1 - cursos de licenciatura, de formação de profissionais para a educação básica, inclusive curso normal superior, destinado à formação de docentes para a educação infantil e para as primeiras séries do ensino fundamental; 
11 - programas de formação pedagógica para portadores de diplomas de educação superior que queiram se dedicar à educação básica;

111 - programas de educação continuada.

$\$ 1^{\circ}$ - A organização de institutos superiores de educação ou a autorização dos cursos referidos nos incisos 1 e 11 deste artigo terão caráter experimental, nos termos do Arto 81 da LDB, e deverão ser aprovados pelo Conselho Estadual de Educação, conforme esta deliberação.

$\$ 2^{\circ}$ - A justificativa do caráter experimental dos institutos superiores de educação e de seus cursos estará no ensaio de novas possibilidades de formação docente, desde que obedecidas as disposições da Lei no 9.394/96.

$\S 3^{\circ}$ - 0 caráter experimental de que trata o $\S 1^{\circ}$ deste Artigo terá o prazo fixado no projeto de Formação de Docente, referido no $\operatorname{Art}^{\circ} 4^{\circ}$ desta Deliberação.

Artigo $3^{\circ}$ - A criação de instituto superior de educação será proposta a partir de um Projeto Institucional fundado na cooperação, no mínimo, entre as seguintes instâncias administrativas:

1 - entidades mantenedoras de escolas municipais de ensino superior ou de escolas estaduais isoladas de ensino superior,

11 - órgãos centrais da administração pública da educação, estadual ou municipal e/ou

111 - universidades públicas.

$\S 1^{\circ}$ - Os termos e as condições de colaboração financeira, administrativa e técnica, no que diz respeito à coordenação e ao funcionamento do instituto superior de educação, serão estabelecidos por instrumento administrativo adequado, aprovado pelo Conselho Estadual de Educação. $\S 2^{\circ}$ - 0 instituto superior de educação, além de cursos de nível superior, poderá manter, administrar ou orientar escolas normais públicas de nível médio, conforme for previsto no Projeto Institucional.

Artigo $4^{\circ}$ - A solicitação de credenciamento de instituto superior de educação será instruída, obrigatoriamente, por um projeto de formação docente para trabalho em escolas de ensino básico e por propostas curriculares dos cursos pretendidos e de desenvolvimento da prática de ensino, com as adequações necessárias aos diferentes niveis da educação básica, segundo as indicações e normas deste Conselho, especialmente a Indicação CEE n 11/97 e a Deliberação CEE $n^{\circ}$ 12/97.

Parágrafo único - A formação para a docência escolar será o eixo integrador para todas as propostas curriculares e disciplinares, bem como para a coordenação pedagógica de cursos, áreas e práticas de ensino, privilegiando o conceito de vida escolar, conforme a reflexão apresentada na Indicação CEE n 07/2000.

Artigo $5^{\circ}$ - A constituição de instituto superior de educação, além das exigências estabelecidas nesta Deliberação, obedecerá as normas já fixadas por este Conselho para as demais instituições de ensino superior do sistema estadual de ensino, no que couber.

Artigo $6^{0}$ - Esta deliberação entrará em vigor após a aprovação pelo Plenário e homologação pela Secretaria de Estado da Educação. 